\title{
Performance Assessment of Thermophotovoltaic Application in Steel Industry
}

\author{
Ehsan Shoaei \\ Research Assistant, Sharif Energy Research Institute, Department of Energy Engineering, \\ Sharif University of Technology, Tehran, Iran \\ E-mail:eshoaei@alum.sharif.edu
}

\begin{abstract}
The potential for using Thermophotovoltaic (TPV) generators as an alternative for recovering energy losses in steel production industry is assessed. A mathematical model for the assessment of the performance of TPV application in the iron and steel industry has been developed. In order to support the mathematical model, a sample TPV apparatus in laboratory scale based on an IR emitter has been designed and assembled. The key modeling parameters of TPV generator include: the open circuit voltage, the short circuit current density and fill factor of the TPV cell. These parameters have been considered in the model as functions of several variables such as: the emitter (hot steel slab) temperature, the cell temperature, the distance between the cells and emitter, the spectral response and the cell energy gap. The External Quantum Efficiency (EQE) as an important indicator of the cell's spectral response is included in the model. Moreover, the variation of the emitter temperature has been considered. Several tests have been carried out for different values of the cell-emitter gap. It has been found that when the GaSb cells are used for energy recovery, a minimum temperature of $873^{\circ} \mathrm{C}$ is required. The upper limit of the emitter temperature is usually determined in steel production process associated with hot rolling process which has a temperature around $1250^{\circ} \mathrm{C}$. Finally, the total efficiency of the system was obtained to $4.12 \%$, when $\mathrm{GaSb}$ cell with temperature of $27^{\circ} \mathrm{C}$ and slab emitters with temperature of $1257^{\circ} \mathrm{C}$ are used. The results of the simulation of the model in a casting process at the Mobarakeh Steel Complex have shown a potential of energy recovery of 26.987 MJ per year.
\end{abstract}

Keywords: Thermophotovoltaic, GaSb cell, iron casting, steel industry, energy recovery

\section{Introduction}

Similar to all the energy conversion concepts, Thermophotovoltaic (TPV) is a method for converting thermal energy (heat radiation) into electrical energy [1]. Since TPV is a technology which requires a heat source with sufficiently high temperature, it can be used in industries where a process is operated under such a condition. A straightforward application of TPV would be waste heat recovery in high temperature industries such as the glass or steel industry. An example of waste heat recovery via TPV cell is the case of the continuous casting of hot rolled steel plates in steel industry. These plates have an initial temperature around $1200{ }^{\circ} \mathrm{C}$ and are 
cooled down to less than $1000{ }^{\circ} \mathrm{C}$. If TPV cells are to be placed above the hot plates during the cooling process, an electric current can be generated via the emission process. It is estimated that the potential power generation of a hot steel slab with a surface area of $50 \mathrm{~m}^{2}$ would be around $440 \mathrm{~kW}[2]$.

Application of TPV generators goes back to the early 1990s when the low band gap infrared (IR) sensitive III-V cells were introduced. The first TPV was the GaSb cell invented in 1989 and then described in 1990 [3].The function of a TPV was then demonstrated by using the commercially available $\mathrm{SiC}$ radiant tube burner. It was then possible to monitor and control the emitted spectrum [4]. Qiu et al. used a TPV system in a combustion chamber where GaSb cells were used [5].Subsequently, the effect of combined usage of TPV and thermoelectric (TE) on enhanced power generation was investigated [6].

The combustion of fuels also provides appropriate heat sources for emitters and part of the heat loss in a combustion chamber may be recovered via a TPV system. Yang et al. studied possible heat recovery based on laboratory tests [7]. The emitted spectrum of a flame in a combustion chamber was also investigated by Li et al. [8, 9]. Pascale et al. examined the integration of TPV and generator of Organic Rankine Cycle and were able to reduce the intensity of the input energy [10]. Cockeram and Hollenbeck used an emitter surface that was coated with substances of high emissivity which led to the development of efficient systems [11]. They showed that an alternative approach would be to use cells that have an energy band gap proportional to the spectrum of the emitter resulting in the enhanced efficiency of a TPV system. As an example, an emitter of $\mathrm{Yb}_{2} \mathrm{O}_{3}$ may be used together with $\mathrm{Cu}$ (In, Ga) $\mathrm{Se}_{2}$ (CIGS) cells that show an energy band gap proportioned to the emitted spectrum [12].

Regulation of the thermal radiation spectrum is an essential element of TPV system. Mostafa et al. used $\mathrm{Si} / \mathrm{SiO}_{2}$ and $\mathrm{Ag} / \mathrm{Sio}_{2}$ photonic crystals to control the spectrum [13].

In three subsequent works, Badescu $[14,15,16]$ analyzed a particular type of TPV device and used a theory integrating the main components of TPV devices. Various combinations of spherical and (disk) plane absorbers and solar cells are analyzed. The components include the primary lens (or mirror), the absorber, the PV cell, and a photon recuperator system. He maximized the TPV efficiency by using three optimization parameters, namely absorber, PV cell 
temperatures, and cell voltage. As the main results of these works, the thermal design has a significant influence on the optimum PV cell band gap. He concluded that in the case of a normal thermal design, the cell temperature is usually high and depends strongly on the band gap. When accurate thermal design is considered, the optimum cell temperature is less than 30 degrees higher than the ambient temperature and decreases with an increase in the band gap.

Bitnar et al. [17] explained another application of a TPV system in a residential central gas heating system. They designed a TPV to supply the electrical power in order to drive the gas heating system truly independent from the electrical grid. This has not yet been commercialized while it can successfully work.

Butcher et al. [18] reported the successful demonstration of a self-powered oil-fired hydronic heating system using TPV technology to provide grid independent operation by producing 119 $\mathrm{W}$ of electrical power.

Bitnar et al. [19] reviewed some related developments of TPV system components such as radiation emitters, filters and photocells and compared theoretical system simulations to experimental results regarding system efficiency and the electrical output power. They suggested novel applications of TPV and discussed the commercial potential of this technology.

Following the trend of research on technical features of TPV systems, industrial application of TPV has been studied by Utlu and Parali [20]. They concluded that the iron and steel industry provides considerable potential of energy recovery via TPV systems. They pointed out that further works is required to demonstrate the performance of a TPV system for a range of slab radiation temperatures in steel industry.

Regarding this application, Johansson et al. [21] proposed the application of TPV in steel and iron production units and presented some opportunities for both integrated and scrap-based steel plants. They evaluated several options from a system perspective and reported more specific measures for two Swedish case companies.

Hence, a model of a TPV system could be developed which would avail itself to further investigation of the potential of energy recovery and the parameters that may affect its realization 
in industry. The development and application of a mathematical model of a TPV system and its verification constitutes the core content of the present paper.

\section{Conceptual model}

The mathematical model of a TPV is founded on the conceptual model of a TPV system as shown in Fig. 1. The conceptual model is deducted as a reference energy system which depicts the flow of energy from primary sources through processing and conversion systems.

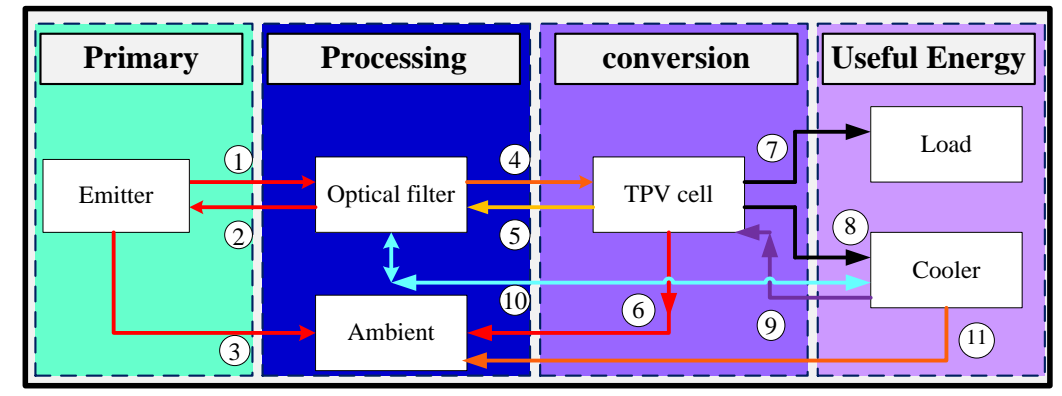

Fig.1.Conceptual model of a typical TPV system

Line number (1) in Fig.1 indicates the transmission of radiated heat from the emitter to the optical filter. Line number (3) shows the heat that is lost to the ambient surrounding area. Since the emitter is placed in free environment, the heat is partially released to the environment via convection and radiation. Line number (2) represents the reflected radiation of the filter toward the emitter. Possible outcomes of incident electromagnetic waves are: transition, reflection and absorption. All the Outcomes are subjected to the type and thickness of the filter. Line number (4) shows the radiation which passes through the filter. The radiation on the cell is segregated into two parts, one part which can be converted into electrical power and the other part includes the absorbed and reflected radiation. The reflected radiation is depicted via line number (5) and the absorbed radiation heats up the cell itself. Consequently, the cell temperature rises and considerably exceeds the ambient temperature which leads to heat loss and is denoted by line number (6). If a filter failure occurs, the cell temperature rises more rapidly. Therefore, a cooling system is required to avoid overheating and dysfunction of the TPV system. Overheating and cooling are singularly represented by line number (9). Line number (8) shows the required power for the cooling system. Line number (11) represents the heat loss through the cooling system. 
Finally, the power generated by the TPV system flows to the end user is indicated by line number (7). Both the cooling system and filter prevent overheating of the cell and their function is shown by line number (10).

\section{Mathematical model}

\subsection{Governing equation}

As an analytical tool, a mathematical model is conceived to study the interrelationships between the various flows as explained in the conceptual model. It could then be applied for parametric analysis and technical evaluation of the performance of the system. Some important functions and equations required for representing the flows in the reference energy system are described here and complementary set of equations included in the model have been presented in Appendix A. An important part of the mathematical model is the estimation of the output energy. The output of the TPV cell has been specified by lines (7) and (8) in the reference energy system and has been represented by equation (1) in appendix A.

The governing equation of the dissipative flows in the whole system, from the emitter in the primary section to the TPV cells in the conversation section, is developed by an integral equation of the short circuit current density, $j_{s c}$, and is defined by Equation 1:

$$
j_{s c}=\int_{\lambda_{0}}^{\lambda_{g}} e_{\lambda b}(\lambda) F_{12} S P_{\lambda} \cdot \tau(\lambda) d \lambda
$$

where the parameters are defined as follows:

$e_{\lambda b}(\lambda)$ : Planck's spectral distribution of emissive power

$F_{12}$ : view factor

$S P_{\lambda}: \quad$ spectral response of the TPV cells

$\tau(\lambda): \quad$ the transmittance of optical filter at a wavelength of $\lambda$

$\lambda_{g}: \quad$ cell band edge

$\lambda_{0}: \quad$ lower wavelength limit

The transmittance coefficient, $\tau(\lambda)$, together with the view factor, $F_{12}$, represent the amount of outgoing energy from the emitter received by the TPV cell. Since the transmittance coefficient includes the dissipation of reflectance and absorbance by the optical filter, it can be applied to 
quantify flows related to lines number (1), (2) and (4) in the conceptual model. The view factor reflects the geometric dissipation and is related to line number (3) in Fig.1. The lower wavelength limit, $\lambda_{0}$, and the cell band edge, $\lambda_{g}$, as the lower and upper limits of the integral equation, reflect the dissipated heat (line number 5 in the conceptual model) due to the cell reflection.

If the emitter is not a black body, such as when it is steel, it becomes necessary to consider its radiation spectrum at different temperatures. Variation of the amount of emissivity with respect to wavelength is shown in Fig.2 for different metals and for steel [22].

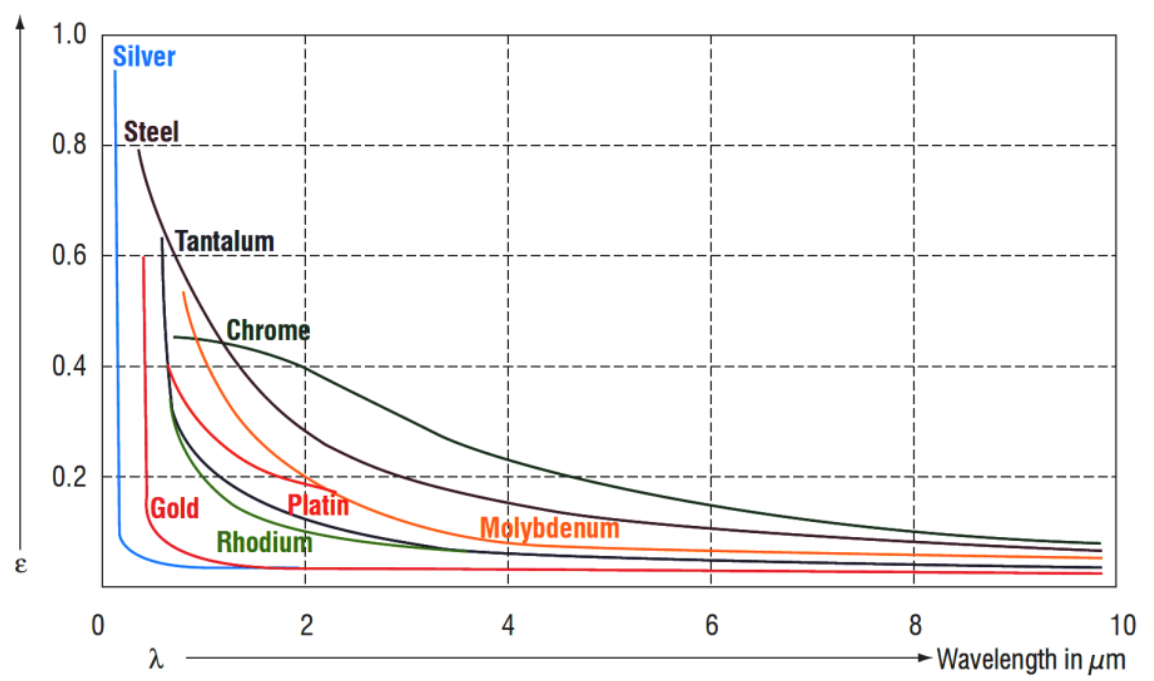

Fig. 2. Variation of the amount of emissivity for different metals [22]

In Equation 1, the spectral response, $S P_{\lambda}$, represents the amount of radiation that the cell converts to electric current. It is function of External Quantum Efficiency (EQE) and reflects the dependency of cell type. The EQE for different semi-conductors that are usually used as TPV materials has been measured in the past as shown in Fig. 3. 


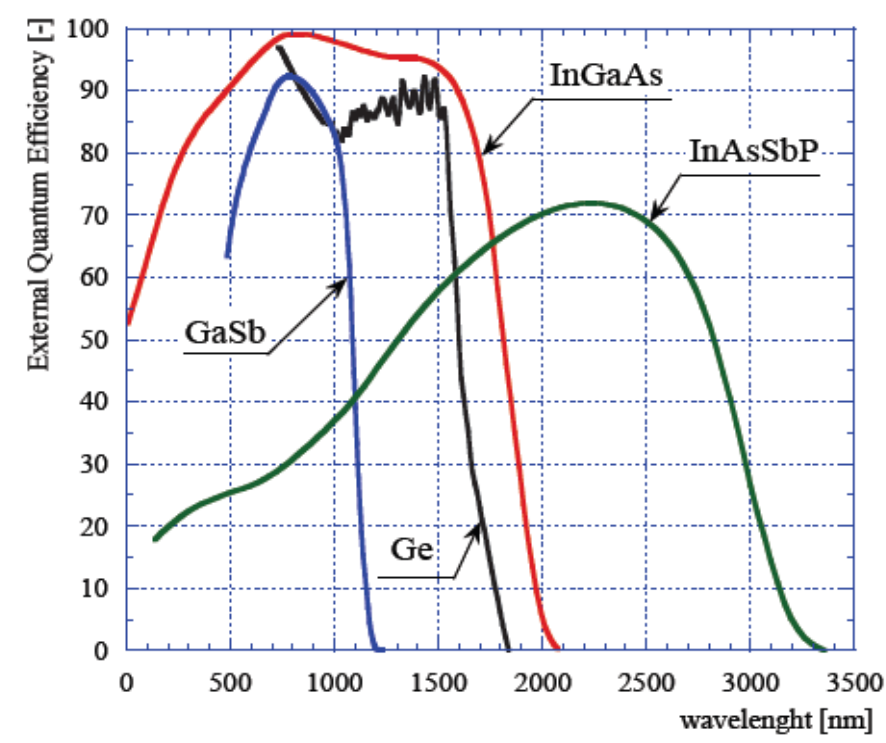

Fig. 3. EQE for different TPV cells with respect to wavelength [23, 24]

The values of EQE for different values of wavelengths which are incident on the cell are assumed to be constant and the corresponding values are tabulated in Table 1 [5].

Table 1. Typical values of EQE with respect to cell energy band gap [5]

\begin{tabular}{cc}
\hline $\boldsymbol{E}_{\boldsymbol{g}}(\boldsymbol{e v})$ & $\boldsymbol{E Q E}$ \\
\hline 1.1 & 0.75 \\
0.72 & 0.75 \\
0.53 & 0.65 \\
\hline
\end{tabular}

EQE directly reflects the amount of cell short circuit density as well as the power density of the cell. On the other hand, EQE represents the probability of absorption of a photon of wavelength $\lambda$ by cell and the production of an electron absorbed with the exit terminal (positive terminal). On the other hand, EQE considers the probability of reflection and absorption of the entrance photon as well as the probability of minority carrier collection (positive holes). Therefore, EQE describes the behavior of p-n junction accurately. In this way, EQE decreases rapidly with increasing in the wavelength (energy decrease). This point has been experimentally verified as indicated in Fig. 3 [23, 24].

However, the value of EQE may be defined as function of wavelength. As can be seen from Fig. 3, the EQE can be quantified with respect to the wavelength through regression analysis. As 
the most widely used cell is of the GaSb type, the data associated with the GaSb cell have been used here; as shown in Fig. 4 [25]. In this figure, the curve associated to the test data has only been used from Ref. [25] and the two fitting curves have been generated by the author.

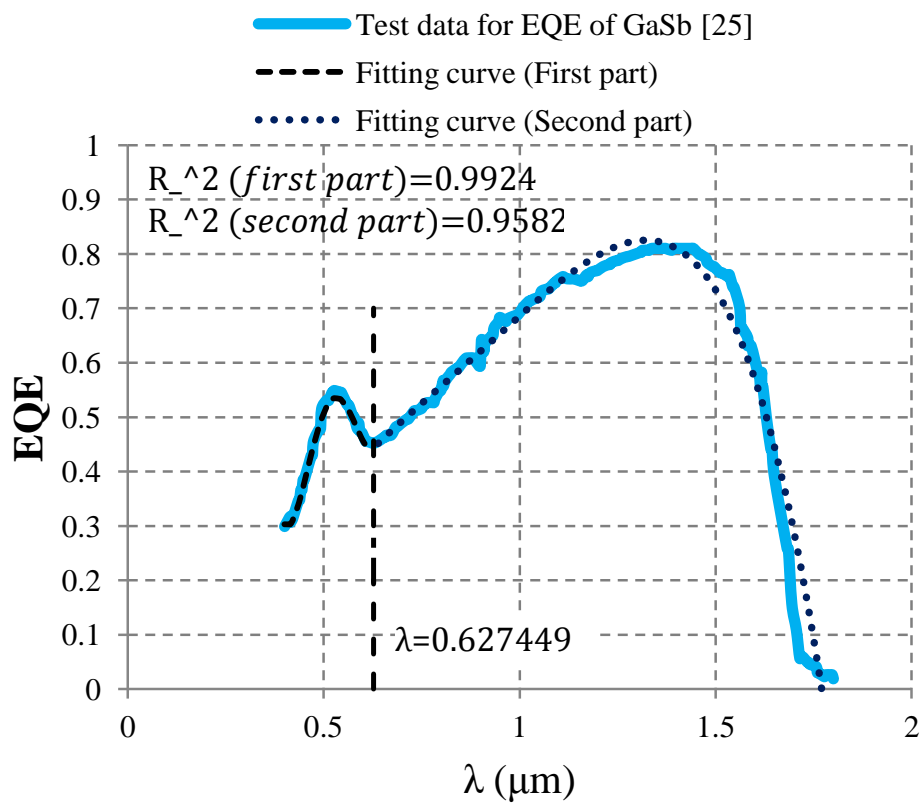

Fig.4. Curves fitted to the experimental data for the EQE of typical GaSb cells.

As shown in Fig. 4, the curve associated to the experimental data can be divided at point $\lambda=0.627449(\mu \mathrm{m})$ into two distinctive parts. The results of the regression analysis is obtained as follows:

$\operatorname{EQE}(\lambda)=$ $\left\{\begin{array}{cll}1187.6 \lambda^{4}-2473.2 \lambda^{3}+1903.8 \lambda^{2}-640.95 \lambda+79.957 & \text { for } & 0.4 \leq \lambda \leq 0.627449 \\ -1.8338 \lambda^{4}+6.3487 \lambda^{3}-8.18 \lambda^{2}+5.2902 \lambda-0.9398 & \text { for } & 0.62745 \leq \lambda \leq 1.8\end{array}\right.$

As $\lambda_{\max }$ is the wavelength related to the maximum radiation at a certain temperature, $\lambda_{0}$ is the smallest convertible wavelength at the same temperature $\left.\left(\lambda_{0}=\frac{\lambda_{\max }}{2.5}\right)\right)$. The average value of the wavelength is given by Eq. (3) as shown below.

$$
\lambda=\frac{\lambda_{\max }+\left(\frac{\lambda_{\max }}{2.5}\right)}{2}=0.7 \lambda_{\max }
$$


According to the Planck's spectral relation, there are certain spectral electromagnetic wavelengths with different irradiance intensities. Wien's displacement law indicates that a wavelength which has maximum irradiance may be asserted. It has been pointed out that EQE is a function of wavelength and temperature. However, the wavelength could be replaced with the average value of the wavelength as specified by Eq. (3). By using of the well-known Wien's displacement law, reformulation of the EQE with respect to the temperature of the emitter (slab) is obtained.

The existence of a filter prevents the mechanism of heat convection. The transient state of the cell is only affected by heat radiation which can be formulated according to the following equation [26]:

$$
\varepsilon_{\text {emit }} \sigma A\left(T_{\text {emit }}^{4}-T_{0}^{4}\right) F_{12}=m_{c} C_{c} \frac{\partial T_{c}}{\partial t}
$$

where $A$ represents the emitter surface, $\varepsilon_{\text {emit }}$ is the emitter emissivity (taken as 0.8 here based on the data related to Fig.2), $\sigma$ is the Stefan-Boltzmann coefficient, $T_{\text {emit }}$ is the emitter temperature, $T_{0}$ is the ambient temperature, $m_{c}$ is the cell mass, $C_{c}$ is the cell specific heat capacity (taken as $0.328 \frac{\mathrm{J}}{\mathrm{gr.K}}$ as recommended in Ref. [27]) and trepresents the time.

On the other hand, the total heat loss includes radiation and convection which can be obtained by Eq. (5)[28].

$$
q_{\text {tot }}=q_{\text {rad }}+q_{\text {conv }}
$$

where $q_{t o t}$ is the total heat transferred to the surrounding environment (line number (3) in Fig. 1), $q_{\text {rad }}$ and $q_{c o n v}$ are the heat quantities transferred by radiation and convection respectively.

Through simultaneous solution of both Eqs. (4) and (5), the temperature of the cell is obtained. The temperature of the cell, $T_{c}$, and the temperature of the emitter, $T_{\text {emit }}$ are two unknown parameters in Eq. (4). To solve Eq. (4), the variation of the temperature of a similar emitter with respect to time can be quantified through utilization of a regression analysis of the experimental measurements [29], as shown in Fig. 5. In this figure, the curve associated to the experimental data has only been used from Ref. [29] and the fitting curve has been generated by the author. 


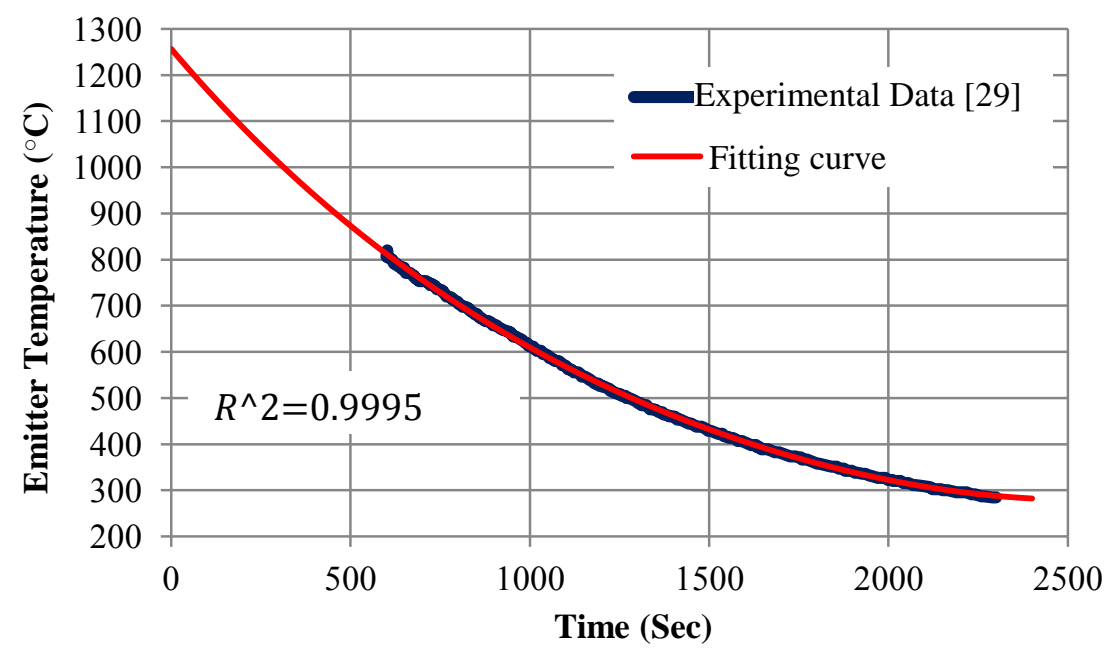

Fig. 5. Air cooling rate of a hot steel slab as a typical emitter.

The following equation for the temperature of the emitter is obtained from the curve fitting:

$$
T_{\text {emit }}(t)=1256 \exp (-0.0007315 t)+0.8095 \exp (0.001827 t)
$$

The original emitter associated with this experimental data (as explained in Ref. [29]) was a cubic steel sample has dimensions of $75 \times 75 \times 50 \mathrm{~mm}$ and the cooling rate temperature had been measured in different points of the sample. In order to consider the effect of the distance between the arrays of cells and the emitter, a view factor is usually used. The cell and emitter surfaces are located in parallel with equal surface areas. The view factor for such a case is given in appendix A.

Finally, two remaining parameters are to be considered. The first parameter is the cell efficiency, $\eta_{c e l l}$, which has been formulated in appendix A. The second parameter is the overall system efficiency of the TPV, $\eta_{T P V}$, and can be estimated by Eq. (7) as follows.

$$
\eta_{T P V}=\frac{p_{e l}}{\varepsilon_{e m i t} \sigma\left(T_{e m i t}^{4}-T_{0}^{4}\right)}
$$

Eq. (7) shows the ratio of the output electrical current to the input radiation power emitted by the slab. 


\subsection{Procedure of solution of the set of equations}

The above mentioned equations are solved in accordance with the procedure as explained in appendix B. The iterative procedure of solving the equations is as follows:

a. The temperature of the emitter is firstly determined.

b. The temperature of the cell is then determined as function of time and the temperature of the emitter.

c. The initial energy band gap of the cell and the distance between the cell and emitter are specified as input parameters.

d. The maximum electrical power density and efficiency of the system are then calculated as output results.

In order to determine to what extent the input parameters affect the performance of the system, parametric analysis is carried out for three different scenarios as follows.

I- Oxidized steel slab is used as the emitter with constant temperature of $1200^{\circ} \mathrm{C}$. The EQE of the system will be constant in this situation.

II- Oxidized steel slab is used as the emitter with initial temperature of $1257^{\circ} \mathrm{Cand}$ the slab is cooled in air. In this case, the EQE of the system is assumed to be constant and equal to $75 \%$.

III- Similar to the latter scenario except that the EQE is assumed to be depend on radiation spectrum wavelength.

The set of equations are solved in accordance with the above mentioned scenarios while the cell-emitter gap and the surface area of the emitter were assumed to be constant and equal to $1 \mathrm{~cm}$ and $1 \mathrm{~m}^{2}$ respectively. It has also been assumed that a typical $\mathrm{GaSb}$ material with initial energy band gap of $0.725 \mathrm{ev}$ is used as TPV cell. The duration of radiation has been assumed to be equal to 8 minutes.

\subsection{Model validation with available reported data}

The accuracy of the mathematical model was compared with the data has been reported in a free catalog of GaSb cells products of the JX-Crystals Company. For this comparison, the data 
associated with input parameters were selected from this catalog and were entered to the model. Then, the results of the model were compared with the experimentally measured data associated with output parameters from that catalog. This comparison is given in Table 2.

It is clear in Table 2 that when the EQE is considered as function of radiation spectrum wavelength, the results of the model are in close agreement with the experimental data. It should be noted that the value of the view factor has not been reported by the company and it was impossible to verify the effects of the view factor and the distance between the cell and the emitter.

Table 2. Comparison of the results of the model with the experimentally measured data of JXCrystals Company for $\mathrm{EQE}=75 \%$ and variable $\mathrm{EQE}$ as function of wavelength.

\begin{tabular}{|c|c|c|c|c|}
\hline \multirow{2}{*}{$\begin{array}{c}\text { Type of } \\
\text { parameters }\end{array}$} & \multirow{2}{*}{$\begin{array}{c}\text { Original } \\
\text { Parameter }\end{array}$} & \multirow{2}{*}{$\begin{array}{l}\text { JX-Crystals } \\
\text { report }^{*}[19]\end{array}$} & \multicolumn{2}{|c|}{ Model results } \\
\hline & & & $E Q E=75 \%$ & Variable EQE \\
\hline \multirow{5}{*}{ Input to model } & $T_{C}\left({ }^{\circ} \mathrm{C}\right)$ & 25 & 25 & 25 \\
\hline & $\boldsymbol{T}_{\text {emit }}\left({ }^{\circ} \mathrm{C}\right)$ & 1200 & 1200 & 1200 \\
\hline & $E_{g}(e v)$ & 0.725 & 0.725 & 0.725 \\
\hline & $\mathrm{D}(\mathbf{c m})$ & unknown & 1 & 1 \\
\hline & $\varepsilon_{\text {emit }}$ & 1 & 1 & 1 \\
\hline \multirow{4}{*}{$\begin{array}{l}\text { Output from } \\
\text { model }\end{array}$} & $V_{o c}(\mathbf{V})$ & 0.472 & 0.4395 & 0.4510 \\
\hline & $j_{s c}\left(\frac{A}{c m^{2}}\right)$ & 2.36 & 2.5577 & 2.5479 \\
\hline & FF & 0.733 & 0.6693 & 0.6782 \\
\hline & $p_{\max }\left(\frac{W}{c m^{2}}\right)$ & 0.8165 & 0.7523 & 0.7794 \\
\hline \multicolumn{5}{|c|}{$\begin{array}{l}\text { Note: } \\
\text { *-Specification of the cell are: GaSb substrate of } 0.65 \mathrm{~mm} \text { thickness, grid wide of } 0.0163 \mathrm{~mm} \text {, grid } \\
\text { spacing of } 0.102 \mathrm{~mm} \text { and active area of } 1.48 \mathrm{~cm}^{2} \text {. } \\
\text {-Specification of the emitter are: blackbody emitter with reasonable view factor. }\end{array}$} \\
\hline
\end{tabular}




\section{Testing of a model of TPV}

\subsection{Conceptual design}

According to the main purposes of the study (i.e., putting the surface of a typical TPV cell in front of an emitter and simulation of thermal radiation from steel plates in an iron casting process), a conceptual experimental model was designed. A schematic view of the model is shown in Fig.6.

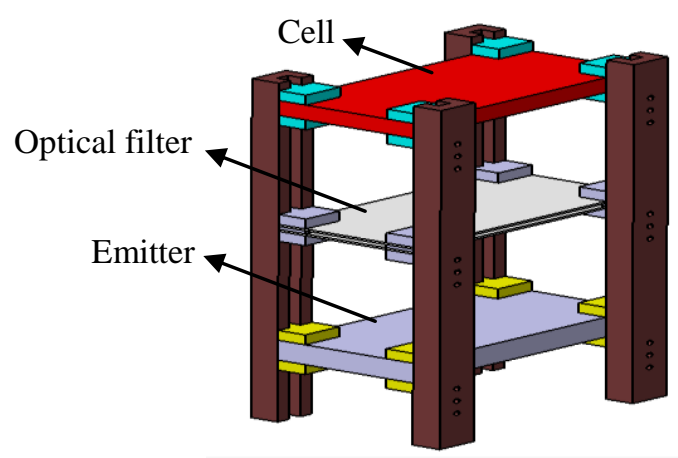

Fig. 6. Schematic view of the conceptual model for TPV assembly

All the layers in Fig. 6 are assumed to be flat and the lower and upper layers are assumed to be the emitter and the TPV cells respectively. The middle layer is assumed to act as a filter for non-convertible spectrum. It is evident from Fig.6 that the possibility of varying the distance between the cell and the emitter has been provided.

\subsection{Design of a setup for three scenarios}

GaSb cells are rarely available commercially and a substitute for GaSb cells is required. Bearing in mind that the operational mechanism of a TPV cell (such as GaSb cell) resembles a diode in an electronic circuit, the experimental model was adjusted according to the following procedure:

- Instead of TPV cells, a laboratory scale model of IR detectors that could simulate the performance of a TPV cell may be used.

- Instead of TPV cells, a laboratory scale model of the well-known red Light Emitting Diode (LED) and IR emitter that could simulate the performance of a TPV cell may be used. LED is 
a semi-conductor diode that emits incoherent narrow band-spectrum of light when electrically biased in forward direction of the p-n junction, as in common LED circuit. This effect is a form of electro luminescence. The color of the emitted light depends on the composition and condition of the semi-conductor material [30].A piece of LED has a small surface which is usually less than $0.1 \mathrm{~mm}^{2}$ [31]. The performance of IR emitters is similar to that of LED except that the IR spectrum is not visible. GaAs is usually used as typical IR emitter [30, 32]. If the required energy for LED is supplied through a convenient spectral radiation, it is possible to use it as an alternative substitute for TPV cells.

- An ordinary solar cell may be used.

Therefore, there are four alternatives for replacing TPV cells as follows:

- IR detectors

- IR emitters

- $\quad$ red LEDs

- $\quad$ ordinary solar cells $(\mathrm{Si})$

\subsection{Test situation}

Two test specimens were prepared based on the above mentioned alternatives. Two different emitters were also used as follows:

- An ordinary Tungsten lamp was used to assess the performance of the alternative devices with respect to the wide spectrum of radiation.

- Thermal electrical resistance with a temperature of $1100^{\circ} \mathrm{Cwas}$ used for simulating the thermal radiation from the slabs (i.e. steel plates).

As shown in Fig. 7, the IR emitter was found to be a better alternative than the others when used in front of a thermal electrical resistance. This fact that IR detectors are only sensitive to a specific range of IR spectrum shows the weak performance of both emitters. In order to improve the performance of the IR emitter, sufficient numbers of emitters were embedded in parallel rows to simulate the surface of a TPV cell as shown in Fig. 8. 


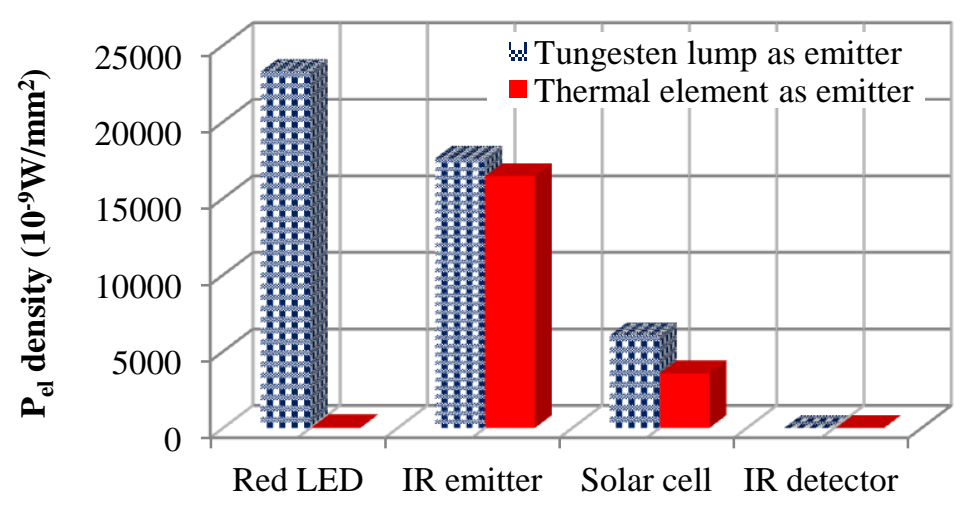

Fig. 7. Performance of different alternatives as substitute for the TPV cell

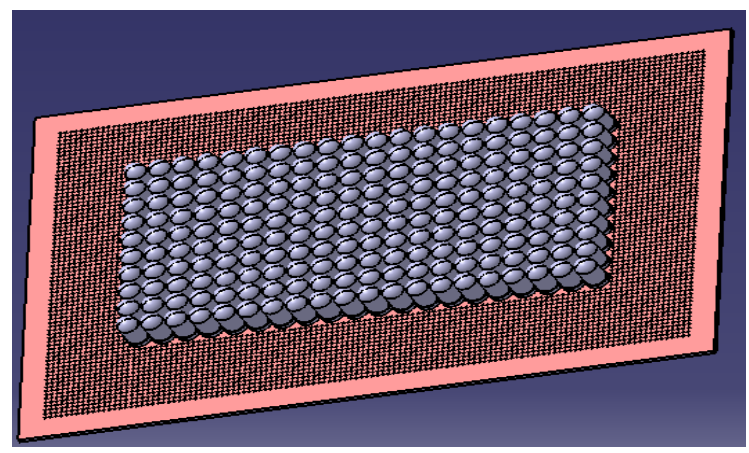

Fig. 8. Pre-designed TPV cell with IR emitter

\subsection{The TPV cell}

The short circuit current density, $\mathrm{j}_{\mathrm{sc}}$, depends on the surface area. Therefore, the connection of the IR emitter was assumed to be in parallel rows in order to achieve an acceptable level of current intensity [33]. Based on this assumption an electronic board consisting of 400 IR emitters was assembled.

\subsection{The Emitter}

In order to simulate the action of hot steel plates as the emitter in the laboratory, four heating elements capable of producing a temperature of $1200^{\circ} \mathrm{C}$ were installed on the free edges of a hollow box made of firebricks as illustrated in Fig. 9. 


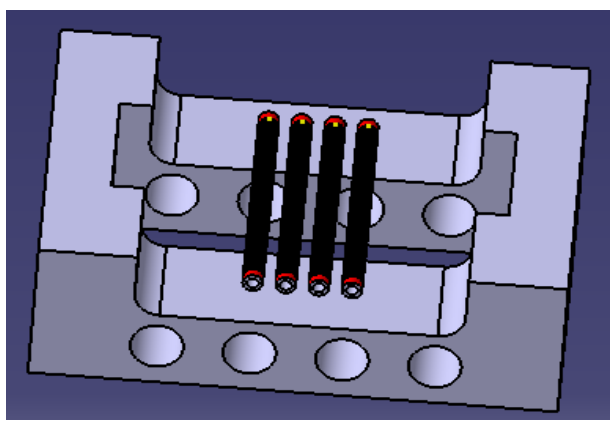

(a)

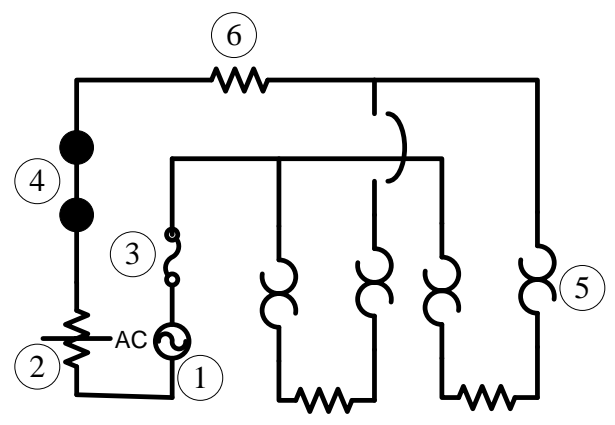

(b)

Fig. 9. Simulating of emitter via heating elements; (a): perspective view, (b): electronic circuit

where, the elements numbered in Fig. 9 (b) are defined as follows.

(1): AC source

(2): attenuator

(3): fuse

(4): electric switch

(5): thermal elements

(6): resistor that indicates wires resistance.

The whole assembly of the TPV device in laboratory scale is shown in Fig. 10.

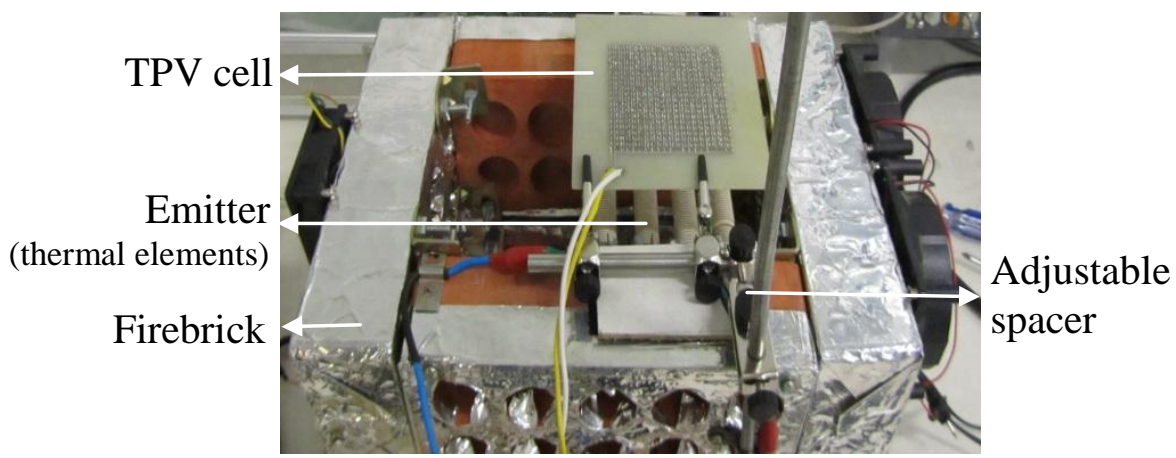

(a) 


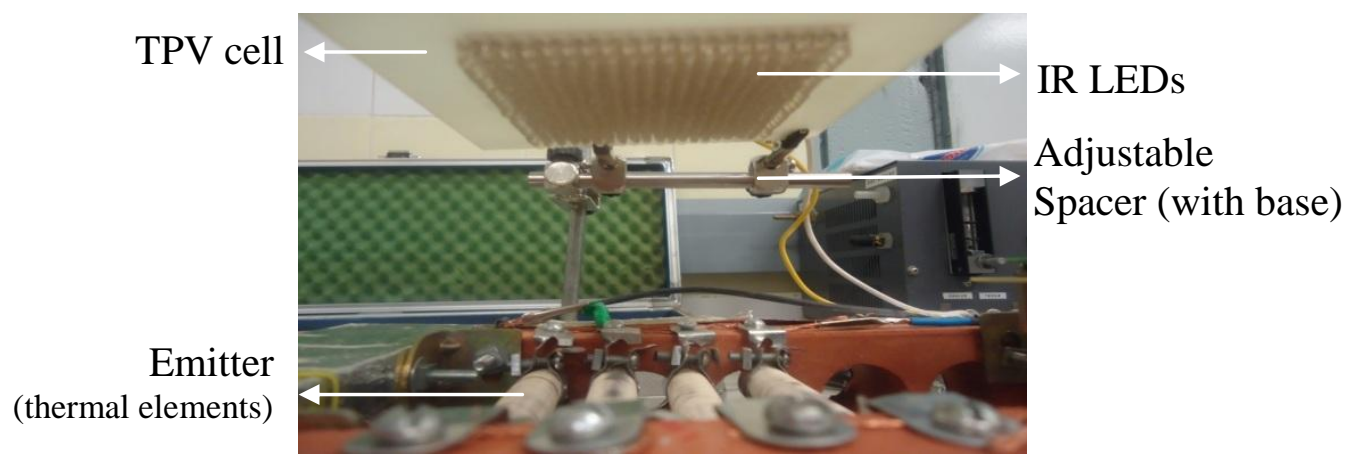

(b)

Fig.10. The whole TPV system;

a): plan view, (b): side view (space between the emitter and cell)

\subsection{Experimental results and model validation}

The above mentioned TPV device was tested several times and the results have been compared with the results of the mathematical model. The results are tabulated in Table 3 . It is clear in Table 3 that the results of the open circuit voltages are in close agreement. It can be seen that the mathematical model overestimates the voltages. This overestimation may be due to the Ohmic losses actually present in the experiment which has not been included in the model. However, the discrepancy between the calculated and the experimentally measured values for the short circuit current is rather low. However, when a solar cell is used for the evaluation of the results, the values associated with the experiment are relatively lower than of the model. The reason might be due to the significant effect of the cell's rapid heat up and this fact that it was rather difficult to put it in front of the emitter. When D or distance between the cell and the emitter is increased (see Table 3) the results become close. The results also indicate that ordinary solar cells are not appropriate as an alternative for TPV materials. 
Table 3. Comparison of the results of the mathematical model with the experimental data

\begin{tabular}{|c|c|c|c|c|c|c|}
\hline \multirow{2}{*}{$\begin{array}{c}\text { Type of } \\
\text { cell }\end{array}$} & \multirow{2}{*}{$\begin{array}{c}\mathrm{D}^{*} \\
(\mathrm{~cm})\end{array}$} & \multirow{2}{*}{$\begin{array}{l}\mathrm{T}_{\text {emit }} \\
\left({ }^{\circ} \mathrm{C}\right)\end{array}$} & \multicolumn{2}{|c|}{$\mathrm{V}_{\mathrm{oc}}(\mathrm{v})$} & \multicolumn{2}{|c|}{$\mathrm{I}_{\mathrm{sc}}(\mathrm{mA})$} \\
\hline & & & Test & Model & Test & Model \\
\hline \multirow{3}{*}{$\begin{array}{c}\text { Fabricated } \\
\text { cell } \\
(I R \text { LED) }\end{array}$} & 4 & 1100 & 0.91 & 1.18 & 6.7 & 7.00 \\
\hline & 8 & 1100 & 0.85 & 1.16 & 3 & 3.27 \\
\hline & 10 & 1100 & 0.841 & 1.15 & 1.40 & 2.37 \\
\hline \multirow{3}{*}{$\begin{array}{l}\text { Solar cell } \\
\quad(\mathrm{Si})\end{array}$} & 4 & 1150 & 0.527 & 0.883 & 88.8 & 238.1 \\
\hline & 8 & 1100 & 0.517 & 0.852 & 61 & 72.87 \\
\hline & 10 & 1100 & 0.5 & 0.842 & 35 & 51.31 \\
\hline
\end{tabular}

* $\mathrm{D}$ is the distance between the cell and the emitter.

\section{Parametric analysis}

One of the most advantages of the developed mathematical model is to perform parametric analysis. Parametric analysis has been carried out to determine to what extent the input parameters affect the performance of the system. Variation of the cell temperature with time and variation of the short circuit density with respect to the emitter temperature are shown in Figs.11 and 12 .

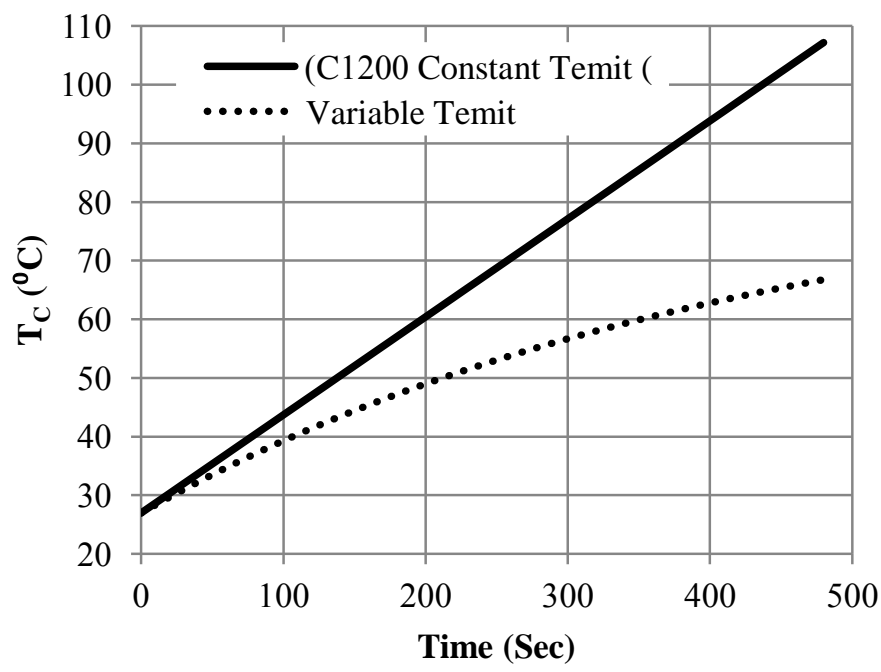

Fig. 11. Variation of the cell temperature with time 


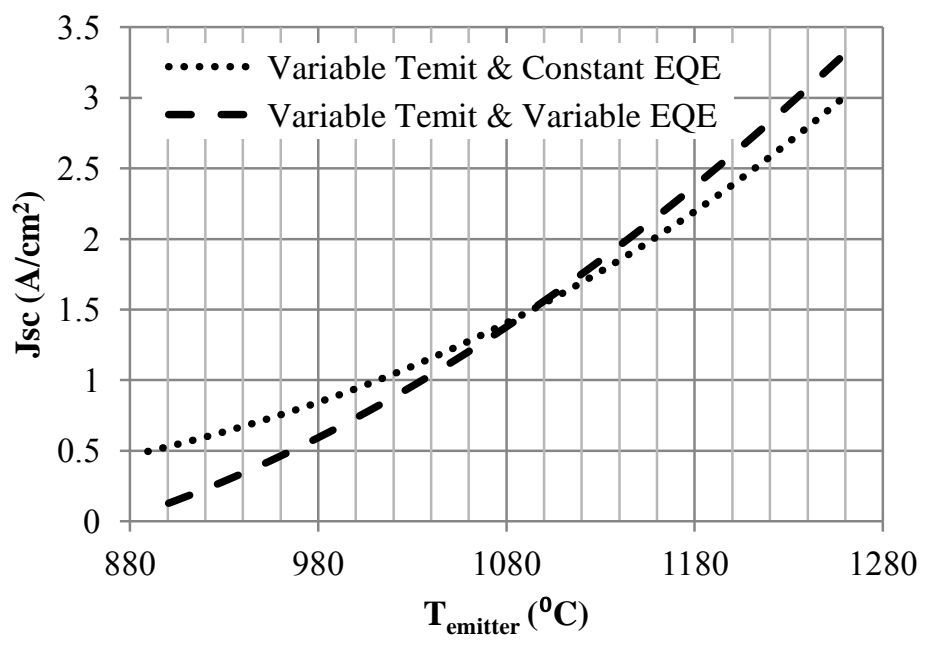

Fig. 12. Variation of short circuit current density with respect to emitter temperature

It is clear from Fig. 12thatthe short circuit current density is directly related to the emitter temperature. On the other hand, as the temperature of the emitter increases, the short circuit current density increases rapidly. The variation of the short circuit current density with time is also shown in Fig.13.

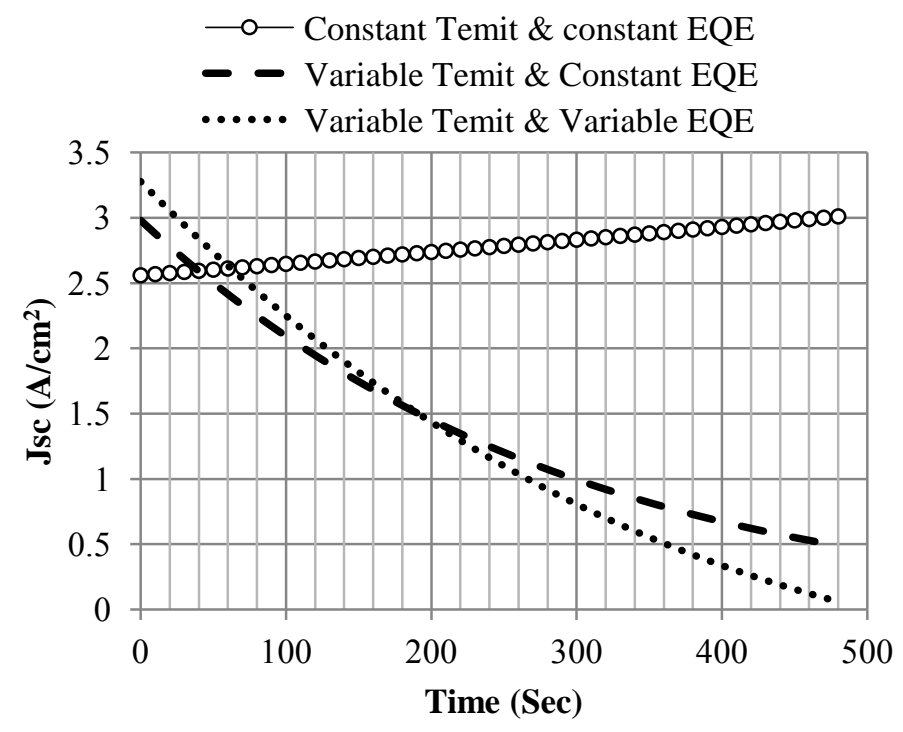

Fig. 13. Variation of short circuit current density with time

It is clear that the effect of the temperature of the cell and emitter have simultaneous impact. An increase in the cell temperature leads to an increase in the recoverable input energy to the cell 
as well as in the short circuit current density. Furthermore, raising the cell temperature increases the short circuit current density slightly and a decrease in the emitter temperature reduces the short circuit current density strictly. Therefore, the effect of the emitter temperature on the short circuit current density is greater than that of the cell temperature.

Fig. 14 shows the impact of the variation of the temperature of the cell and emitter on the open circuit voltage.

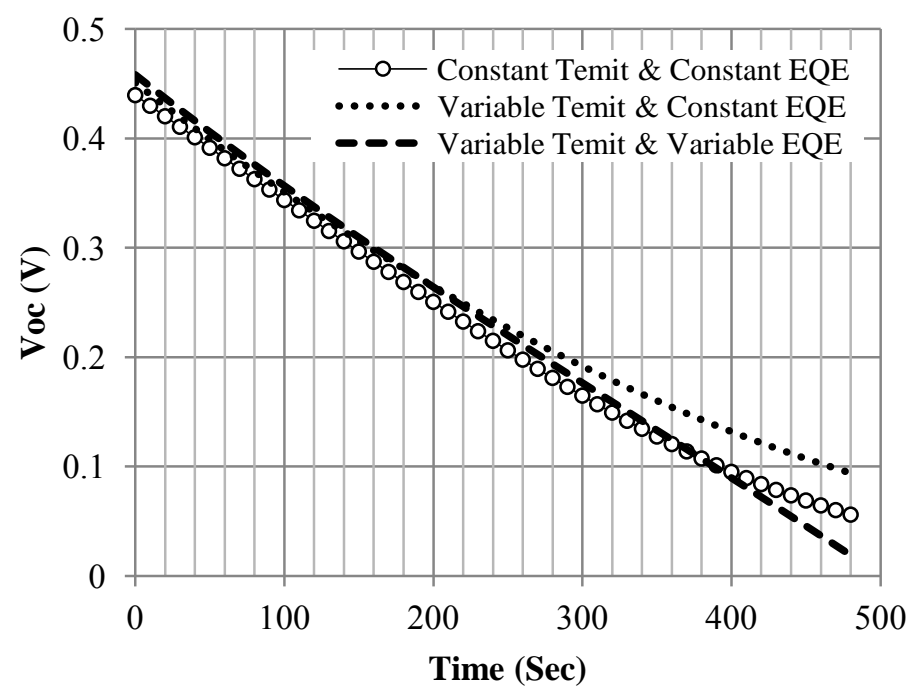

Fig. 14. Variation of open circuit voltage with time

Fig. 14 shows that the variation of the EQE has no effect on the open circuit voltage except at low values of the emitter temperature. It can also be observed that the effect of the cell temperature on the open circuit voltage is more significant than that of the emitter temperature.

The variation of the cell electric power output density, $P_{e l}$, with time is shown in Fig.15. An increase in the cell temperature or decrease in the emitter temperature results in the reduction of the cell electric power output density. Fig. 15 indicates a situation with constant value for the temperature of the emitter. It shows that the electric power is reduced to zero in a finite time when the cell temperature is increased rapidly. 


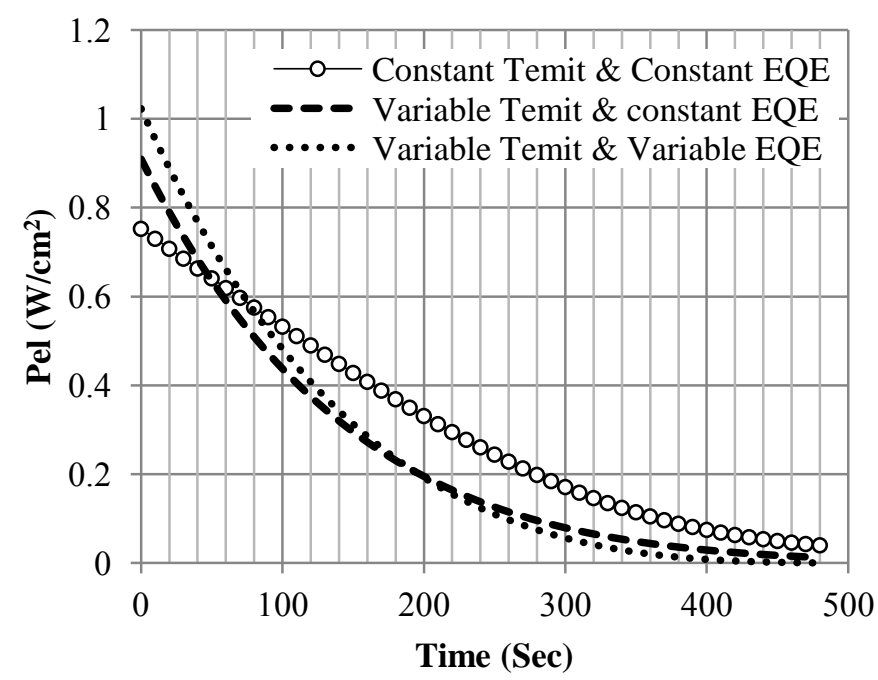

Fig. 15. Variation of the cell electric power output density with time

The efficiency of each cell is seen to be $9.72 \%$ when $\mathrm{EQE}=75 \%$ and the temperatures of the emitter and cell are equal to $1257^{\circ} \mathrm{C}$ and $27^{\circ} \mathrm{C}$ respectively. On the other hand, when variable $\mathrm{EQE}$ is considered, the efficiency of the cell equals $10.93 \%$. Variation of the efficiency of the cell with respect to the emitter temperature is shown in Fig.16.

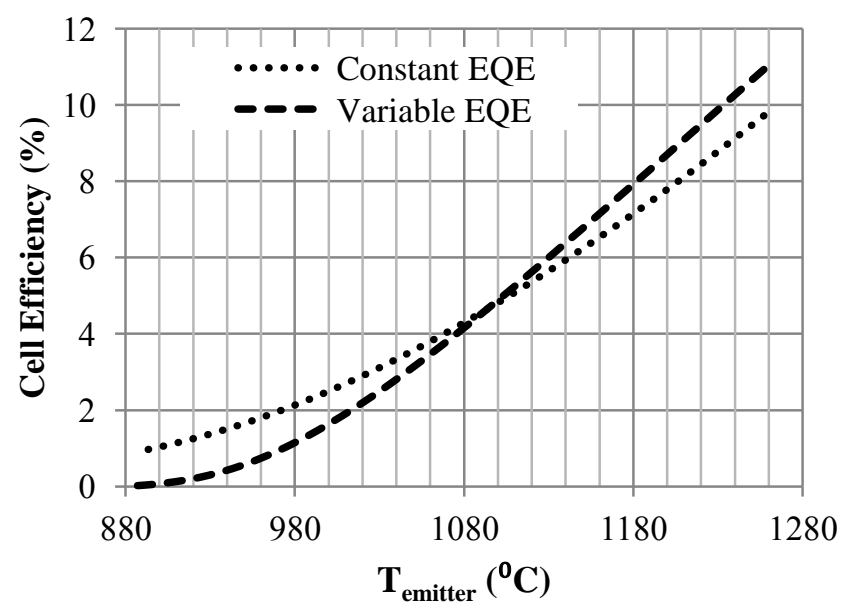

Fig. 16. Variation of the efficiency of the cell with respect to the emitter temperature

As shown in Fig.16, an increase in the emitter temperature leads to an increase in the cell efficiency. Variation of the cell efficiency with respect to the cell temperature is shown in Fig. 17. 


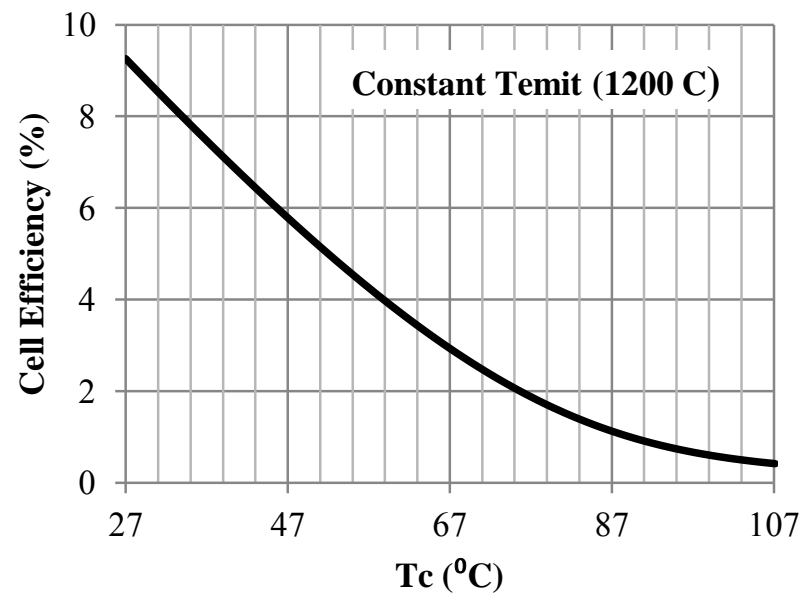

Fig. 17. Variation of the cell efficiency with respect to the cell temperature atconstant $T_{\text {emit }}$

When the temperature of the emitter is kept constant, an increase in the cell temperature causes a decrease in the efficiency of the cell (Fig. 17).

Finally, variation of the system efficiency with time is shown in Fig. 18. The overall system efficiency is changed via an increase in the cell temperature or a decrease in the emitter temperature. In a specific case (i.e., the optimum point), when the temperatures of the emitter and the cell are equal to $1257^{\circ} \mathrm{C}$ and $27^{\circ} \mathrm{C}$ respectively and the distance between the cell and the slab becomes $1 \mathrm{~cm}$ and $\mathrm{EQEis}$ assumed to be variable, the overall system efficiency will be equal to $4.12 \%$.

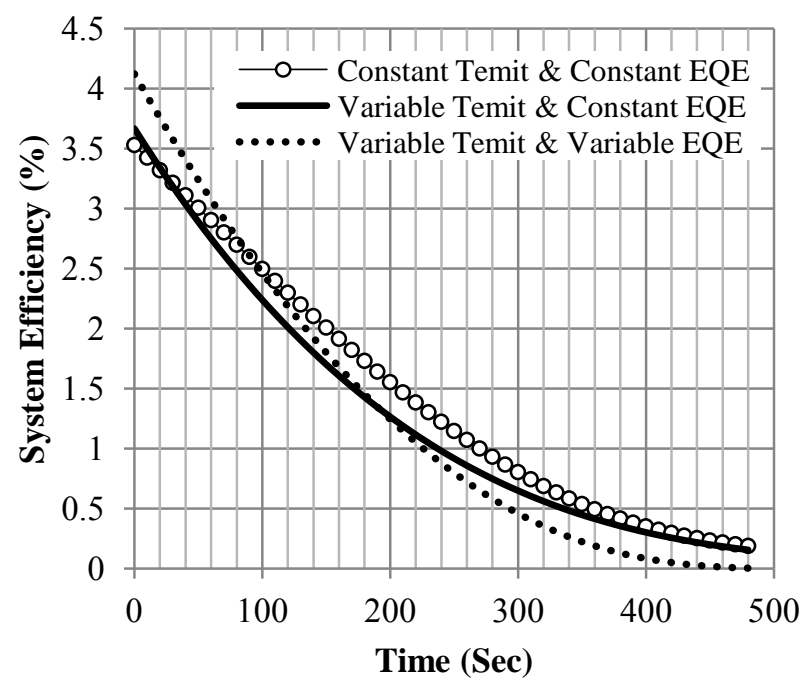

Fig. 18. Variation of the system efficiency with time 


\section{Active temperature}

The minimum temperature of the emitter at which the TPV can be activated is the point where the short circuit current density tends to zero. If the minimum value for the short circuit current density is assumed to be equal to $1 \mathrm{~mA}$ per $\mathrm{cm}^{2}$ of the cell, the minimum required temperature of the emitter is found to be $873^{\circ} \mathrm{C}\left(1146^{\circ} \mathrm{K}\right)$.

\section{Techno-economic analysis in a case project}

The mathematical model has been used as a tool for evaluating the potential of energy recovery in the iron casting unit of the Mobarakeh Steel Complex (the largest hot rolled steel plate production unit in Iran). The general characteristics of the iron casting process at this unit are summarized in Table 4. These characteristics have been used as input data for the model.

Table 4. Boundary condition of iron casting workshop

\begin{tabular}{lc}
\hline The temperature of the site (near the casting machine) & $57^{\circ} \mathrm{C}$ \\
The distance between the cells and the emitter (hot steel plates) & $5(\mathrm{~cm})$ \\
The width of the steel plate as the emitter & $100(\mathrm{~cm})$ \\
The temperature of the emitter & Constant \\
The External Quantum Efficiency, EQE & Variable \\
\hline
\end{tabular}

According to the reports released by this complex, the total amount of steel slab production was about 5.35 million tons in 2012. The initial temperature of the steel slabs at the outlet of the casting machine (before cutting) is about $900^{\circ} \mathrm{C}$ and the corresponding surface area is approximately $64 \mathrm{~m}^{2}$. It is estimated that a value of $3.3129 \mathrm{TJ}$ of heat is radiated annually which can be partly recovered via TPV. The ambient temperature around the slabs has been measured around to $57^{\circ} \mathrm{C}$ (see Table 4). With assuming that the temperature of the cell is $57^{\circ} \mathrm{C}$ and the temperature of the slab is $900^{\circ} \mathrm{C}$, it has been obtained from the model that the amount of energy recovered by a typical cell at a distance of $1 \mathrm{~cm}$ above the slab will be $26.987 \mathrm{MJ}(7.5 \mathrm{kWh})$ per 
year. In order to recover this amount of energy via TPV, about to $324870 \mathrm{GaSb}$ cells are required which cost 16 million USD. Economic analysis on applicability of the TPV system indicates that the initial investment on implementing the system is difficult to reverse at the price of electricity less than 6.7 cent/kWh. Further economic assessment reveals that it will be economically feasible under the following condition:

- continuous casting units be used

- minimum price of electricity becomes 12.8 cents $/ \mathrm{kWh}$

- the price of GaSb cells be reduced by $75 \%$.

\section{Conclusion}

In this paper, for the first time, a well-established mathematical model for the assessment of the performance of a typical TPV generator in steel and iron industry has been developed. The model has been firstly validated with published experimentally measured data of the JX-Crystal Co. Supporting experimental measurements have confirmed the applicability of the model for the assessment of energy recovery in steel industry. Parametric analysis has been done to determine the effects of the main input parameters on the efficiency of the whole system. Finally, the model has then been applied to a real scale case project and the results have been demonstrated both technically and economically, while it is not economically feasible now. The main results of the present work are summarized as follows:

- An increase in the temperature of the emitter causes an increase in the input power to the cell. On the other hand, the temperature of the emitter is directly proportional with the input power to the cell by a fourth power relationship.

- The short circuit current density is directly proportional with the emitter temperature.

- In the case of variable $\mathrm{EQE}$, the short circuit current density in a temperature range higher than $1100^{\circ} \mathrm{C}$ will be increased and vice versa.

- Assuming that the minimum value of the short circuit current density is $1 \mathrm{~mA} \mathrm{per} \mathrm{cm}^{2}$, the minimum required value of the emitter temperature was found equal to $873^{\circ} \mathrm{C}$. 
- When the temperature of the simulated hot steel slab equal to $1257^{\circ} \mathrm{C}$ and the temperature of the cell equal to $27^{\circ} \mathrm{C}$, the system efficiency reaches $4.12 \%$. This is an optimal situation for the system efficiency. This value decreases rapidly when the gap between the cell and the slab increases.

Finally, the results of the model applied to the iron casting unit of the Mobarakeh Steel Complex; that produces steel slabs with an initial temperature of $900^{\circ} \mathrm{C}$; shows that an annual energy recovery of $3.3129 \mathrm{TJ}$ is achieved. Although the economic analysis of the application of TPV systems in such industries indicates that the amount of energy recovered via such TPV systems cannot, at present, be economically feasible, the results of this study can be useful for further research towards an optimal situation in this regard.

\section{Acknowledgment}

The author would like to express his special thanks to Prof. Saboohi, the Director of Sharif Energy Research Institute of the Department of Energy Engineering of Sharif University of Technology for his valuable comments and suggestions in this research. The author would like to thanks to the department for instrumental supports. 


\section{References}

[1] D., Chubb, Fundamentals of thermophotovoltaic energy conversion. (2007) Access Online via Elsevier.

[2] J., van der Heide, 1.28 - Thermophotovoltaics, in Comprehensive Renewable Energy, S. Editor-in-Chief: Ali, (2012), Elsevier: Oxford. 603-618.

[3] Fraas L., Avery J., Gee J., Emery K., et. al., "Over 35\% Efficient GaAs/GaSb Stacked Concentrator Cell Assemblies for Terrestrial Applications", $21^{\text {st }}$ IEEE PV Specialist Conference, (1990) p. 190.

[4] Fraas, L. and L. Minkin. TPV history from 1990 to present \& future trends. in AIP Conference Proceedings. (2007).

[5] Qiu, K., et al., Generation of electricity using InGaAsSb and GaSb TPV cells in combustion-driven radiant sources. Solar Energy Materials and Solar Cells (2006) 90(1) 68-81.

[6] Qiu, K. and A. Hayden, Development of a novel cascading TPV and TE power generation system. Applied Energy (2012) 91(1) 304-308.

[7] Yang, W., et al., An advanced micro modular combustor-radiator with heat recuperation for micro-TPV system application. Applied Energy (2012) 97 749-753.

[8] Li, Y.-H., et al., Development of a high-flame-luminosity thermophotovoltaic power system. Chemical Engineering Journal (2010) 162(1) 307-313.

[9] Li, Y.-H., et al., Concept and combustion characteristics of the high-luminescence flame for thermophotovoltaic systems. Proceedings of the Combustion Institute (2011) 33(2) 3447-3454.

[10] De Pascale, A., et al., Integration between a thermophotovoltaic generator and an Organic Rankine Cycle. Applied Energy (2012) 97: p. 695-703.

[11] Cockeram, B. and J. Hollenbeck, The spectral emittance and long-term thermal stability of coatings for thermophotovoltaic (TPV) radiator applications. Surface and Coatings Technology (2002)157(2) 274-281.

[12] Durisch, W. and B. Bitnar, Novel thin film thermophotovoltaic system. Solar Energy Materials and Solar Cells (2010) 94(6) 960-965.

[13] Mostafa, S.I., N.H. Rafat, and S.A. El-Naggar, One-dimensional metallic-dielectric $\left(\mathrm{Ag} / \mathrm{SiO}_{2}\right)$ photonic crystals filter for thermophotovoltaic applications. Renewable Energy (2012) 45 245-250.

[14] Badescu V., Thermodynamic theory of thermophotovoltaic solar energy conversion, Journal of Applied Physics (2001) 906476 
[15] Badescu V., Thermal design influence on the performance of solar thermophotovoltaic devices, International Journal of Sustainable Energy (2003) 23 (1-2) 63-81.

[16] Badescu V., Upper bounds for solar thermophotovoltaic efficiency, Renewable Energy (2005) 30(2) 211-225.

[17]Bitnar B, Durisch W, von Roth F, Palfinger G, Sigg H, Gruetzmacher D, et al. Progress in TPV converters. In: Marti A, Luque A, editors. Next generation photovoltaics: high efficiency through full spectrum utilization. Institute of Physics (2004) 223-245. ISBN: 0750309059.

[18]Butcher TA, Hammonds JS, Horne E, Kamath B, Carpenter J, Woods DR. Heat transfer and thermophotovoltaic power generation in oil-fired heating systems. Applied Energy (2011) 88 1543-1551.

[19] Bitnar, B., W. Durisch, and R. Holzner, Thermophotovoltaics on the move to applications. Applied Energy (2013) 105 430-438.

[20] Utlu, Z. and U. Parali, Investigation of the potential of thermophotovoltaic heat recovery for the Turkish industrial sector. Energy Conversion and Management (2013) 74 308322.

[21] Johansson, M.T. and M. Söderström, Options for the Swedish steel industry-energy efficiency measures and fuel conversion. Energy (2011) 36(1) 191-198.

[22] www.micro-epsilon.com.

[23] Bosia, M., et al. Thermophotovoltaic Generation: A state of the art review. in Proceedings of the 25th int conf on efficiency, cost, optimization, simulation and environmental impact of energy systems (2012).

[24] Chan, W., et al., Modeling low-bandgap thermophotovoltaic diodes for high-efficiency portable power generators. Solar Energy Materials and Solar Cells (2010) 94(3) 509-514.

[25] www.JX-crystals/SaleItems.com.

[26] Butcher, T., et al., Heat transfer and thermophotovoltaic power generation in oil-fired heating systems. Applied Energy (2011) 88(5) 1543-1548.

[27] Kumar, P.S.D.a.H.L.B.a.V., The physics and technology of gallium antimonide: An emerging optoelectronic material. Applied Physics Reviews (1997) 20 81(9) 5822-5870.

[28] P.Incropera, F., INTRODUCTION TO HEAT TRANSFER. (1990).

[29] Allazadeh, M.R., The Effect of Cooling Rate on the Microstructure Configuration of Continuously Cast Steel Slabs. 2009, University of Pittsburgh. 
[30] Singh, S.C., BASICS OF LIGHT EMITTING DIODES, CHARACTERIZATIONS AND APPLICATIONS, 2013.

[31] Moreno, I. and C.-C. Sun, Modeling the radiation pattern of LEDs. Opt. Express (2008) 16(3) $1808-1819$.

[32] Schubert, E.F., T. Gessmann, and J.K. Kim, Light emitting diodes. 2005, Wiley Online Library.

[33] Kalogirou, S.A., Solar energy engineering: processes and systems. 2009, Academic Press.

[34] Chan, W., Towards a High-Efficiency Micro-Thermophotovoltaic Generator, in Department of Electrical Engineering and Computer Science. June 2010, MASSACHUSETTS INSTITUTE OF TECHNOLOGY (MIT). 


\section{Appendix A: Complementary equations}

The maximum electrical power density, $P_{e l}$, of a cell is defined by Eq. (A.1) [5]:

$$
P_{e l}=V_{o c} \times F F \times j_{s c}
$$

where the parameters are defined as follows:

$\mathrm{FF}=$ fill factor

$V_{o c}=$ open circuit voltage

The cell band edge, $\lambda_{g}$, is given by Eq. (A.2) [33]:

$$
\lambda_{g}=\frac{h c}{E_{g}}
$$

where $c, h$ and $E_{g}$ are respectively the speed of light, Planck's constant and the cell energy band gap. The lower wavelength limit, $\lambda_{0}$, may be approximated by Eq. (A.3) [5]:

$$
\lambda_{0}=\frac{\lambda_{g}}{2.5}
$$

If $\lambda_{g}$ is made equal to the maximum energy band gap, the value of $\lambda_{0}$ ought to be determined in a way that all the smaller wavelengths are considered.

The spectral response, $S P_{\lambda}$, determines the amount of radiation that the cell converts to electric current and is defined by Eq. (A.4) [5]:

$$
S P_{\lambda}=\frac{E Q E q_{0} \lambda}{h c}, \lambda \leq \lambda_{g}
$$

where $E Q E$ is the External Quantum Efficiency, $q_{0}$ is the elementary charge and $\lambda$ is the wavelength.

The open circuit voltage, $V_{o c}$, and the saturation current density, $j_{0}$, are given by Eqs. (A.5) and (A.6) respectively [5]:

$$
\begin{aligned}
& V_{o c}=\frac{\Gamma k T_{c}}{q_{0}} \ln \left(\frac{j_{s c}}{j_{0}}+1\right) \\
& j_{0}=1.5 \times 10^{5} \exp \left(\frac{-E_{g}}{k T_{c}}\right)
\end{aligned}
$$


where $k$ is the Boltzmann factor, $\Gamma$ is the diode ideality factor (taken as 1.0 here) and $T_{c}$ is the cell temperature.

The variation of energy band gap for semi-conductor materials with respect to its temperature is represented by Eq. (A.7) [34]:

$$
E_{g}(T)=E_{g}(0)-\frac{\alpha_{c} T^{2}}{T+\beta_{c}}
$$

where $E_{g}(0)$ is the initial cell energy bandgap and $\alpha_{c}$ and $\beta_{c}$ are constant parameters that are related to cell type .

The fill factor is given by Eq. (A.8) [5]:

$$
\mathrm{FF}=\beta \frac{\mathrm{v}-\ln (\mathrm{v}+0.72)}{\mathrm{v}+1} \quad, \mathrm{v}=\frac{q_{0} \mathrm{~V}_{\mathrm{oc}}}{\mathrm{kT}_{\mathrm{c}}}
$$

where $\beta$ is the amendment coefficient. Here, $\beta$ is assumed to be 0.96 [5].

The cell and emitter surfaces are located parallel and have equal surface areas as shown in Fig. A.1.

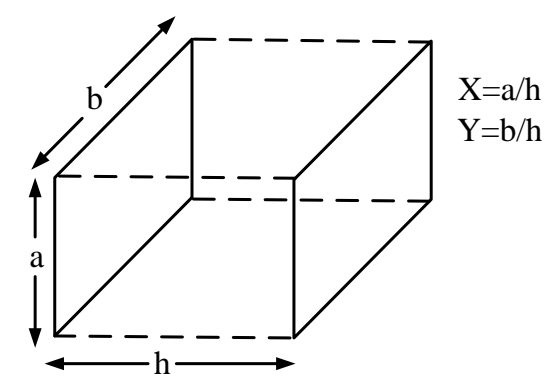

Fig. A.1. Geometry of the emitter and cell [1]

The view factor for the case similar to the box in Fig.A.1 could be obtained via Eq. (A.9) $[1]$ :

$$
\begin{aligned}
& F_{12}= \\
& \frac{2}{\pi X Y}\left\{\ln \left[\frac{\left(1+X^{2}\right)\left(1+Y^{2}\right)}{1+X^{2}+Y^{2}}\right]^{\frac{1}{2}}+X \sqrt{1+Y^{2}} \tan ^{-1}\left(\frac{X}{\sqrt{1+Y^{2}}}\right)+Y \sqrt{1+X^{2}} \tan ^{-1}\left(\frac{Y}{\sqrt{1+X^{2}}}\right)-\right. \\
& \left.X \tan ^{-1} X-Y \tan ^{-1} Y\right\}
\end{aligned}
$$


Finally, the cell efficiency, $\eta_{\text {cell }}$, is given by Eq. (A.10) [5]:

$$
\eta_{\text {cell }}=\frac{P_{e l}}{\int_{\lambda_{0}}^{\lambda g} e_{\lambda b}(\lambda) F_{12} \tau(\lambda) d \lambda}
$$




\section{Appendix B: The solving algorithm}

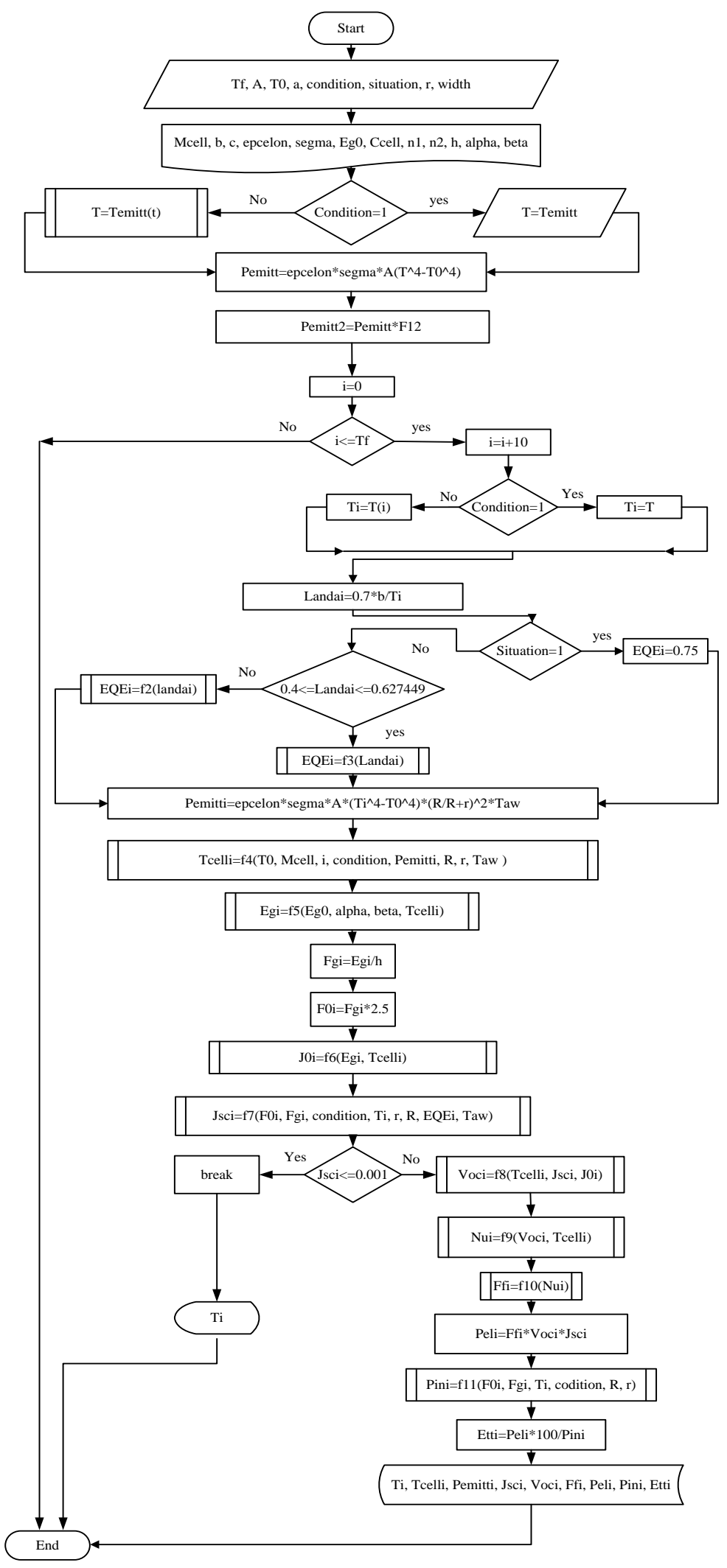

